\title{
AS INQUIETAÇÕES DA MODERNIDADE
}

\author{
Maria Suely Paula da Silva \\ Professora da Rede Pública Municipal. Mestranda em Ciências Sociais - UFRN. \\ supaula2002@yahoo.com.br
}

Recebido em agosto/2004 e Aceito em outubro/2004

\begin{abstract}
RESUMO
A época em que vivemos, chamada por alguns de pós-modernidade, é vista pela maioria dos autores nacionais e internacionais, como a época das incertezas, das fragmentações, das desconstruções, do vazio, do niilismo, da substituição da ética pela estética, do consumo de sensações, etc... Enfim, uma época de transição, de transformação, onde o projeto da modernidade parece ter se cumprido em excesso ou ser insuficiente para solucionar os problemas que assolam a humanidade. Há o argumento de que estamos entrando em uma nova era e, nessa transição, surgem vários termos, como sociedade de informação, sociedade de consumo, sociedade pós-industrial. O presente artigo busca avaliar se há a exaustão do paradigma moderno e o surgimento de um novo paradigma, observando quais são os pressupostos e fundamentos filosóficos da modernidade e em que medida estes se encontram transformados, alterados no contexto de uma nova articulação da realidade, uma pós-modernidade.
\end{abstract}

Palavras-have: Sociedade, Modernidade, Pós-modernidade, Modernização reflexiva.

\section{THE CONCERNS OF MODERN TIMES}

\begin{abstract}
The epoch we live in, which some call post modern, is depicted by most national and international authors as a time of uncertainty, fragmentation, deconstruction, void, nihilism, substitution of the ethical by the aesthetic, consumption of sensations, etc...In the end, ours is seen as an epoch of transition and transformation, when the project of modern times seems to have over-fulfilled its mission or to be insufficient to solve the problems that batter Mankind. The argument that we are entering a new era is accompanied by various terms, like the information society, the consumption society, the post-industrial society...This paper tries to evaluate whether or not the paradigm of modern times has run its course and a new paradigm is evolving, by observing the philosophical presumptions and foundations of the modern paradigm and seeing how much those have been changed or altered in the context of a new articulation with reality in post modern times.
\end{abstract}

Key words: Society, Modern, Post Modern, Reflexive Modernization. 


\section{AS INQUIETAÇÕES DA MODERNIDADE}

\section{CONSIDERAÇÕES INICIAIS}

“Lugar de ser feliz não é supermercado”.

A frase retirada da música "Piercing”, do compositor Zeca Baleiro, nos faz refletir. Retrata quanto o consumismo assola a humanidade nos tempos atuais, tempos modernos, (ou pósmoderno?), cheios de incertezas, riscos, desesperanças, é o que observamos no dia-a-dia, nas conversas com os amigos, nas notícias veiculadas pela mídia, nas atitudes das pessoas. Que tempos são esses? Tempos angustiantes, sem projetos, sem crenças, sem horizontes? A angústia sem dúvida é inerente ao ser humano, mas certamente é fomentada e potencializada pelas condições socioeconômicas da atualidade. Hoje o panorama social favorece a eclosão de padecimentos mais difusos, menos centrados em sintomas claramente identificáveis, mas ligados à sensação de que “a vida não dá certo”. A angústia se expressa de muitas maneiras, uma das quais é a sensação de desamparo e de desorientação diante das exigências da vida. É muito comum vivenciarmos uma dolorosa sensação de impotência, advinda da perda de parâmetros e da fragmentação da experiência cotidiana em segmentos que não se comunicam nem formam um todo coerente.

$\mathrm{O}$ indivíduo tende a sentir-se confuso diante da velocidade com que o seu mundo se modifica, que torna nebulosa sua própria inserção nele e faz evaporar todas as certezas. A vivência da perda associa-se, assim, à proliferação de apelos ao consumo e ao sucesso. Estamos vivendo uma cultura de consumo generalizada, a qual faz com que os indivíduos, mesmo angustiados, perplexos e inseguros, estejam mais interessados em "Escolher entre um Citröen e um Renalt, ou entre os produtos de Estée Lauder e os de Helena Rubisntein" (CASTORIADIS apud SOARES, 1999), do que com sua condição de Ser e Estar-nomundo.

A época em que vivemos, chamada por alguns de pós-modernidade, é apontada pela maioria dos autores nacionais e internacionais, como a época das incertezas, das fragmentações, das desconstruções, da troca de valores, do vazio, do niilismo, da deserção, do imediatismo, do hedonismo, da substituição da ética pela estética, do narcisismo, do consumo de sensações, etc... Enfim, uma época de transição, de transformação, onde o projeto da modernidade parece ter se cumprido em excesso ou ser insuficiente para solucionar os problemas que assolam a humanidade. Segundo Boa Ventura de Souza Santos, em seu livro Pela Mão de Alice (1995), vivemos uma condição de perplexidade diante de inúmeros dilemas nos mais diversos campos do saber e do viver. Que, além de serem fonte de angústia e desconforto, são também desafios à imaginação, à criatividade e ao pensamento.

O que se percebe no nosso cotidiano é uma grande angústia. Mas por que tanta angústia? porque esse sentimento de vazio, de incompletude? Parece que falta entusiasmo, crença em algo, num projeto político, numa idéia, numa causa. Hoje não se acredita mais em grandes mudanças, pelo menos naquelas de antes, que nos faziam vibrar, sonhar, sonho de um mundo mais justo, mais igualitário nas questões sociais, econômicas, políticas, de respeito as diferenças, mais digno, menos consumista, enfim, num mundo onde as pessoas fossem mais felizes. E acreditávamos não por sermos ingênuos, mas porque tínhamos algumas certezas que nos eram dadas pelas teorias sociais, pelo conhecimento científico, pelos movimentos sociais e políticos, pelos estudiosos que admirávamos, pela história enfim. 
Essa situação pode ser um reflexo desses tempos que vivemos, como muito bem coloca Robert Kurz no texto $O$ tédio mortal da modernidade:

Essa ilimitada falta de conteúdo e objetivo anuncia o esgotamento intelectual e cultural do sistema social dominante. Tal como o homem só pode se constituir como indivíduo dentro da sociedade, como indivíduo ele só pode cultivar conteúdos e objetivos sociais. O indivíduo voltado exclusivamente a si mesmo é por força vazio, incapaz de forjar conteúdos próprios; seus projetos se esvaem na trivialidade fútil. No fim do século 20 a modernidade mergulhou num tédio mortal. (KURZ,1999, p.10)

Estamos sofrendo desse tédio mortal. As propostas modernas que visavam, entre outros objetivos, a prosperidade social a partir do desenvolvimento da técnica, da ciência aplicada e do livre mercado. Não se concretizaram. Se por um lado a ciência e a técnica avançaram, talvez, além do esperado, a contrapartida de prosperidade social e cultural não se concretizou. Avaliar se esses objetivos ainda são pertinentes e se a modernidade ainda tem condições de cumpri-los é uma tarefa árdua que necessita ser feita, para que se possa compreender a existência, configuração e, mesmo necessidade, de um novo paradigma dito pós-moderno.

Para avaliar se há a exaustão do paradigma moderno e o surgimento de um novo paradigma, cumpre observar quais são os pressupostos e fundamentos filosóficos da modernidade e em que medida estes se encontram transformados, alterados no contexto de uma nova articulação da realidade, uma pós-modernidade.

\section{MODERNIDADE E PÓS-MODERNIDADE}

Iniciamos com a definição simples de Anthony Giddens da modernidade: "modernidade refere-se a estilo, costume de vida ou organização social que emergiram na Europa a partir do século XVII, e que ulteriormente se tornaram mais ou menos mundiais em sua influência” (GIDDENS, 1991, p.11). Hoje existem muitos argumentos de que estamos entrando em uma nova era e, nessa transição, surgem vários termos, como sociedade de informação ou a sociedade de consumo, outros vão mais além, demonstram a idéia de encerramento, aí entra "pós-modernidade, pós-modernismo, sociedade pós-industrial” e assim por diante.

Jean-Francois Lyotard um dos pensadores da pós-modernidade, simplificando ao extremo, considera como "pós-moderna" a incredulidade em relação aos meta-relatos. As metanarrativas são os grandes esquemas histórico-filosóficos de verdade e liberdade, história e progresso, razão e revolução, ciência e industrialismo criados pela era moderna. O declínio das meta-narrativas de caráter totalizante, universais e atemporais, impede a afirmação de qualquer grande verdade. Essa rejeição das grandes narrativas desvaloriza o passado. $\mathrm{O}$ passado não é mais uma história na qual poderíamos nos situar. Isto faz da pósmodernidade o lugar, por excelência, do efêmero, do fugaz, portanto, da incerteza. Como nos diz Kumar:

Temos aqui o mundo pós-moderno: um mundo de presente eterno, sem origem ou destino, passado ou futuro; um mundo no qual é impossível achar um centro ou qualquer ponto ou perspectiva do 
qual seja possível olhá-lo firmemente e considerá-lo como um todo; um mundo em que tudo que se apresenta é temporário, mutável ou tem o caráter de formas locais de conhecimento e experiência. Aqui não há estruturas profundas, nenhuma causa secreta ou final; tudo é (ou não é) o que parece na superfície. É um fim à modernidade e a tudo que ela prometeu e propôs. (KUMAR, 1997, p.152)

Ulrich Beck e Anthony Giddens (1997), partilham da opinião de que as sociedades modernas, chegaram a um estado de alta ou radicalizada modernidade, na qual a característica dominante é um elevado grau de reflexividade. Isto é, as sociedades modernas chegaram a um ponto em que são obrigadas a refletir sobre si mesmas e que, ao mesmo tempo, desenvolveram a capacidade de refletir retrospectivamente sobre si mesmas. Os antigos modelos de desenvolvimento das sociedades modernas criam agora problemas e dilemas tão fundamentais que questionam qualquer movimento de acordo com esses princípios. É a chamada modernização reflexiva, determinada por grandes mudanças sociais. São essas mudanças que irão desnudar o nível de insegurança, de perigo, enfim, a sociedade de risco (Beck, 1997, p.15), que é uma fase do desenvolvimento da sociedade moderna, em que os riscos sociais, políticos, econômicos e individuais tendem cada vez mais a escapar das instituições para o controle e a proteção da sociedade industrial. O resultado mais radical ocorre quando as instituições da sociedade industrial tornam-se produtoras e legitimadoras das ameaças que não podem controlar, onde fenômenos como o impacto da globalização, as mudanças na vida cotidiana e pessoal e o surgimento da sociedade pós-tradicional escapam do escopo da modernidade ocidental e alcançam o mundo todo, e a um só tempo.

Para Giddens, essa sensação de que não se pode obter um conhecimento sistemático sobre a organização social é resultado de estarmos sendo apanhados por eventos que não compreendemos plenamente, e que parecem estar fora de nosso controle. E isto não é o suficiente para inventarmos novos termos e sim olhar para a natureza da própria modernidade e analisar como isto veio a ocorrer.

Em As Conseqüências da Modernidade (1991), Anthony Giddens desenvolve uma interpretação "descontinuísta" do desenvolvimento social moderno. Para ele é preciso capturar a natureza dessas descontinuidades para poder analisar o que é realmente a modernidade e diagnosticar suas conseqüências para nós no presente. Para identificação dessas descontinuidades que separam as instituições sociais modernas das ordens sociais tradicionais, devemos observar algumas características: o ritmo da mudança - as mudanças em todas as esferas, em condições de modernidade, acontecem numa velocidade extrema; o escopo da mudança - as interconexões de diferentes áreas, geram ondas de transformação social que penetram o mundo todo; e a natureza intrínseca das instituições modernas - a modernização não transcorre de maneira única e uniforme pelas diversas regiões do globo. Para Giddens (1997), a globalização não é uma mera continuação da expansão do capitalismo e do Ocidente. Ela se investe de uma qualidade diferente, já que sua instantaneidade, interrelaciona o global e o local e não tende a uma única direção, produzindo, também, novas formas de estratificação social, mas com conseqüências opostas em diferentes localidades. Por outro lado, Giddens não percebe uma homogeneização cultural como conseqüência da globalização, mas ao contrário, ele considera que nesse nível são produzidas as diásporas culturais. 
O que se destaca em Giddens é que ele procura desenvolver uma análise institucional da ambigüidade da vida moderna, centralizando a discussão nos temas de segurança versus perigo e confiança versus risco, que caracterizariam essa fase da modernização reflexiva. Observa-se que, através do desenvolvimento a longo prazo do sistema industrial, criou-se um mundo onde predomina a incerteza artificial, a modernização reflexiva, que se contrapõe à "modernização simples" (GIDDENS, 1997), cuja dominação impediu a revelação das incertezas, produzindo-se a imagem do progresso capitalista ou industrial como totalmente previsível, tanto nas teses conservadoras como nas revolucionárias.

Um fato que diferencia a nova realidade globalizada pós-tradicional da modernidade radicalizada é o desencaixe, ou seja, o esvaziamento dos contextos locais de ação e sua reestruturação através de extensões indefinidas de tempo-espaço, produzindo uma forte destradicionalização. Isso implica a conformação da abstração e da generalidade com a constituição de sistemas peritos e fichas simbólicas. Os sistemas peritos "são os sistemas de excelência técnica, ou competência profissional, que organizam grandes áreas dos ambientes material e social em que vivemos hoje, oferecendo garantias/confiança das nossas perspectivas, ao mesmo tempo em que removem as relações sociais das imediações do seu contexto" (GIDDENS, 1991, p.35). Por fichas simbólicas, Giddens (1991) define os meios de intercâmbio que circulam sem levar em conta as características dos grupos ou indivíduos. ${ }^{1}$ Estes elementos caracterizam bem o distanciamento produzido na alta modernidade e dão origem a instituições cuja atuação abrange vastas distâncias e depende de mecanismos de coordenação temporal-espacial novas, baseadas na confiança, fornecidas por esse sistema de peritos. Neste sentido, Giddens observa que sob o duplo impacto das influências da globalização e destradicionalização, diversos aspectos da vida cotidiana ficaram esvaziados de habilidades desenvolvidas localmente, sendo invadidos por sistemas peritos de conhecimento, pois os sistemas abstratos incluem não só a tecnologia, mas também qualquer forma de conhecimento perito que substitua as artes ou capacidades locais.

As análises de Giddens são bastante otimista, ele vê a vida cotidiana, dentro da alta modernidade, como um complexo ativo de reações aos sistemas abstratos, que envolve tanto apropriações como perdas. Confiança e risco, oportunidade e perigo são características polares, paradoxais da modernidade e permeiam todos os aspectos da vida cotidiana, ninguém pode estar completamente de fora diante das condições da modernidade. Essas condições podem produzir ativismo ao invés de privatismo em muitas circunstâncias, isso por causa da reflexividade inerente à modernidade e porque há muitas oportunidades para a organização coletiva no interior dos sistemas. A modernização reflexiva possibilita processos ativos de auto-identidade, vê como possível e necessário o engajamento político coordenado, tanto num nível global como local, enfim, para Giddens, na modernização reflexiva, além da compulsividade está a oportunidade de se desenvolverem formas autênticas de vida humana.

\section{CONSIDERAÇÕES FINAIS}

As tendências de mudança em nosso mundo, onde tudo é novo e confuso, não pode ser razão para renunciarmos a nossa capacidade de entender e encontrar sentido, para buscar entender seu inter-relacionamento. Penso que é possível observar, analisar e teorizar e,

\footnotetext{
${ }^{1}$ Um exemplo significativo é o dinheiro, ele não se relaciona ao tempo como um fluxo, mas exatamente como um meio de vincular tempo-espaço associando instantaneidade e adiamento, presença e ausência, sendo fundamental para o desencaixe da atividade econômica atual (GIDDENS,1991:33).
} 
assim, ajudar a construir um mundo diferente e melhor, mesmo não dando respostas, mas questionando, buscando e se angustiando estaremos fazendo algo.

A modernização reflexiva vislumbra a possibilidade do entendimento e da necessidade de se produzir interpretações que acompanhem as descontinuidades da modernidade produzidas pela grande rapidez e ritmo de mudança da vida moderna. Como alerta Scott Lash (1997, p.237), não se deve negligenciar as fontes culturais/hermenêuticas do ser moderno, ou, ainda, a vida cotidiana das pessoas comuns, igualmente relevantes no processo, e Giddens complementa:

Poucas pessoas no mundo, podem continuar sem consciência do fato de que suas atividades locais são influenciadas, e às vezes até determinadas por acontecimentos ou organismos distantes [...] As ações cotidianas de um indivíduo produzem conseqüências globais [....] Esta extraordinária - e acelerada - relação entre as decisões do dia-a dia e os resultados globais, juntamente com o seu reverso, a influência das ordens globais sobre a vida individual, compõem o principal tema da nova agenda. As conexões envolvidas são freqüentemente muito próximas. Coletividades e agrupamentos intermediários de todos os tipos, incluindo o estado, não desaparecem em conseqüência disso, mas realmente tendem a ser reorganizados ou reformulados. (GIDDENS, 1997, p.75)

Num mundo em que tudo é incerto - paz, segurança, relações sociais e humanas, trabalho, etc. - temos um grande desafio, viver bem, mesmo angustiados.

Para finalizar farei referência ao filme As Invasões bárbaras, do diretor canadense, Denys Arcand, que fala de morte, desilusão e filosofia. O filme é uma espécie de continuação de O Declínio do Império Americano, que abalou os espectadores nos anos 80 ao criticar o capitalismo e as relações entre homens e mulheres com alta dose de bom humor e cinismo - o que permanece em As Invasões Bárbaras. O filme discorre sobre um tema seríssimo. Mesmo nos dando a sensação de que vivemos numa civilização prestes a ruir, as rupturas de tom, sorrisos, amizade e calor, fazem a história pesada, ganhar leveza. Segundo o diretor, o filme é um relato pessoal, de tudo aquilo em que a geração dos anos 60 e 70 acreditava e que não viu acontecer, o que suscita um sentimento de desilusão e de descrença, fazendo com que, ao olhar para o futuro, sejamos assaltados por um imenso vazio. Apesar do clima de que tudo está chegando ao fim, o filme sugere ou nos deixa a lição que mesmo com tudo falhando, cultivar e preservar os relacionamentos pessoais ainda é algo válido que merece ser almejado. "De certa forma éramos todos marxistas ou feministas, e sinto que temos uma certa nostalgia dessas crenças - ou de ter crenças -, ainda que essa nostalgia venha temperada pela satisfação de ver que as amizades resistiram às mudanças” (ARCAND, 2004).

\section{REFERÊNCIAS BIBLIOGRÁFICAS}

BECK, U. “A Reinvenção da Política: Rumo a uma Teoria da Modernização Reflexiva”. IN: BECK, U.; GIDDENS, A. \& LASH, S. Modernização Reflexiva. São Paulo: Editora da Universidade Estadual Paulista, 1997. 
BRITO, Daniel C.; RIBEIRO, Tânia Guimarães. A modernização na era das incertezas: crise e desafios da teoria social. Ambiente \& Sociedade - Vol. V - no 2 - ago./dez. 2002 - Vol. VI - no 1 - jan./jul. 2003

GIDDENS, A. As Conseqüiências da Modernidade. São Paulo: Editora da Universidade Estadual Paulista, 1991.

GIDDENS, A. “A Vida em uma Sociedade Pós-Tradicional”. IN: BECK, U.; GIDDENS, A. \& LASH, S. Modernização Reflexiva. São Paulo: Editora da Universidade Estadual Paulista, 1997.

LASH, S. “A Reflexividade e Seus Duplos: estrutura, estética, comunidade”. IN: BECK, U.; GIDDENS, A. \& LASH, S. Modernização Reflexiva. São Paulo: Editora da Universidade Estadual Paulista, 1997.

LYOTARD, J.F. O Pós-Moderno. 3. ed. Rio de Janeiro: José Olympio, 1990.

KUMAR, Krishan. Da Sociedade Pós-Industrial à Pós-Moderna: Novas teorias sobre o mundo contemporâneo. Rio de Janeiro: Jorge Zahar Editor, 1997. 04-158.

KURZ, Robert. O tédio mortal da modernidade. Folha de São Paulo Caderno Mais! página 10 - 28/11/1999.

REVISTA VEJA, Denys Arcand: Entrevista páginas amarelas: 11-15. 04/02/2004

SANTOS, Boaventura de Souza. Pela Mão de Alice. $2^{a}$ ed. São Paulo, editora Cortez. 1996

SOARES, Holgonsi. As três dimensões temporais: Certeza da incerteza. A razão jornal, 29/04/99. RS 